\title{
SPECT/CT radiation dosimetry
}

\author{
M. Ferrari · P. De Marco $\cdot$ D. Origgi · \\ G. Pedroli
}

Received: 20 October 2014/ Accepted: 24 November 2014/Published online: 6 December 2014

(C) Italian Association of Nuclear Medicine and Molecular Imaging 2014

\begin{abstract}
Single-photon emission computed tomography combined with X-ray computed tomography (SPECT/CT) improves diagnostic accuracy by allowing better localization and definition of scintigraphic findings. However, the combined acquisition of functional and anatomical images can substantially increase radiation exposure to patients, particularly when using a hybrid system with diagnostic CT capabilities. At the same time, the introduction of new SPECT and CT reconstruction techniques (based on the use of iterative algorithms), and of CT automatic dose modulation techniques, has opened the way for possible reductions in patient dose and/or improvements of image quality. It is, therefore, essential to carefully balance the diagnostic needs and the radiation protection requirements, optimizing the choice of radiopharmaceutical and administered activity, and the image acquisition and processing modalities both in SPECT and in CT. This is particularly important in the case of pediatric examinations. In short, to maximize benefit to patients, SPECT/CT studies have to be optimized, adopting dose-reduction measures both from CT and SPECT practices. In SPECT, shorter lived gamma emitters should be preferred and the amount of activity administered must be carefully adjusted to the patient's size. In CT, scanning parameters (scanning length, tube current, tube voltage, filtration, collimation, slice thickness, pitch, automatic dose modulation method, reconstruction technique, and image processing) must be chosen carefully,
\end{abstract}

M. Ferrari · P. De Marco · D. Origgi · G. Pedroli ( $₫)$ Medical Physics Unit, European Institute of Oncology, Milan, Italy

e-mail: guido.pedroli@ieo.it

P. De Marco

Specialization School of Medical Physics, University of Milan, Milan, Italy remembering that normally the scanned images are used only for the purposes of attenuation correction and/or a more precise localization of scintigraphic findings, which require lower quality and consequently entail a lower dose to the patient. On the other hand, good quality diagnostic CT images, obtained at higher dose levels, are necessary if a diagnostic $\mathrm{CT}$ examination must still be planned for the patient. The purpose of this review on SPECT/CT radiation dosimetry is to provide updated information on the total effective dose and total equivalent doses to critical organs due to both radiopharmaceutical administration and CT scan modality for both adults and pediatric patients. The use of new solid-state detectors (cadmium zinc telluride) for SPECT cameras will also be considered. Finally, the means of easily determining SPECT/CT dose to patients will be provided.

Keywords SPECT/CT - Radiation dosimetry - Effective dose $\cdot$ Injected activity

\section{Introduction}

As is well known in general radiology and in diagnostic nuclear medicine, radiation doses must be kept as low as is reasonably achievable consistent with obtaining the required medical information. It is, therefore, very important, in all diagnostic procedures, to adjust radiation doses in order to meet this principle. It is particularly important in the case of pediatric examinations.

In recent years, there has been a constant development of the use of SPECT/CT hybrid systems which combine single-photon emission computed tomography (SPECT) with X-ray computed tomography (CT). These systems improve diagnostic accuracy by allowing better 
localization and definition of scintigraphic findings. However, the combined acquisition of functional and anatomical images can substantially increase radiation exposure to patients, particularly when using a hybrid system with diagnostic CT capabilities.

With SPECT/CT, the radiation dose to patients is the sum of the radiation dose due to the radiopharmaceutical administered for SPECT imaging and the radiation dose from the CT component of the study. Thus in SPECT/CT procedures, it is essential to carefully balance the diagnostic needs and the radiation protection requirements through optimization of both SPECT and CT practices. For this reason, the radiopharmaceutical used and its administered activity as well as the image acquisition and processing modalities both in SPECT and in CT must be carefully evaluated.

The purpose of this review on SPECT/CT radiation dosimetry is to provide updated information on the total effective doses and total equivalent doses to critical organs due to both radiopharmaceutical administration and the CT scan modality with reference to both adult and pediatric patients. To this end, the two components of the study, SPECT and CT, are dealt with separately.

In this context, we highlight the effect of new dosereduction techniques and also consider the use of new solid-state detectors (CdZnTe) in cardiac SPECT imaging.

Finally, the means of easily determining SPECT/CT dose to patients will be provided.

\section{The SPECT component}

\section{Administered activities}

An adequate clinical result of a SPECT examination depends primarily on the statistical content of the images.

Thus, the administered activity is the most important factor determining SPECT image quality. However, the administered activity must be decided on the basis of a correct evaluation procedure, taking into account several clinical and technical aspects that also depend on patient characteristics. The most important factors that must be taken into account are scan duration, characteristics of the imaging system, image reconstruction, and image processing modalities.

Table 1 shows the injected activities for the most common SPECT/CT examinations recommended by the European Association of Nuclear Medicine (EAMN) procedural guidelines [1-8], as listed on the EANM website (http://www.eanm.org/publications/guidelines/index.php), and by the Society of Nuclear Medicine and Molecular Imaging (SNMMI) in its Nuclear Medicine Radiation Dose Tool [9].
These values are compared with those obtained by Brix et al. [10] based on an evaluation of SPECT examinations carried out in 48 German hospitals and private practices in 2007-2008 and those obtained in a UK nuclear medicine survey carried out in 2003-2004 by Hart et al. [11]. They are also compared with those reported by Mettler et al. [12] as current representative activity values administered in diagnostic nuclear medicine, derived from peer-reviewed scientific literature published in the United States, Canada, Japan, Australia, and Western Europe between 1980 and 2007, and with other published data on currently injected activities in SPECT/CT examinations [13-17].

As can be seen from Table 1, the administered activity ranges recommended by the EAMN are generally aligned with those recommended by the SNMMI [9] with the sole exception of parathyroid examinations.

The data reported by Brix et al. [10] and Hart et al. [11] are generally aligned with the ranges recommended by the EANM and sometimes even lower, while a larger variability is present in the data reported by the other authors [12-17]. In any case, it has to be kept in mind that administered activities must respect any diagnostic reference levels established by the national legislation.

\section{Radiation doses}

As is well known, the risk incurred by people exposed to ionizing radiation can be represented by the dosimetric quantity known as the "effective dose."

Effective doses due to the administration of a radiopharmaceutical can be calculated simply by multiplying the administered activities by the effective dose coefficients per unit of administered activity. Table 2 shows the dose coefficients reported by the SNMMI. However, these coefficients generally refer to the values recommended by the ICRP publications 53 [20], 80 [21], and 106 [22] which are based on the old definition of effective dose (ICRP 60 [23]) and not on the most recent one (ICRP 103 [24]). Therefore, the dose coefficients calculated by Brix et al. [10] taking into account the new effective dose definition (ICRP 103) are also shown together with the mean absorbed dose per unit of administered activity to the critical organ [9].

Measures to reduce the radiation dose in SPECT

As mentioned above, the radiation dose to the patient in SPECT examinations depends, in addition to the activity administered and the scan time, on several other factors. Among these we highlight in particular the following ones, which can be targeted in order to reduce the dose. 


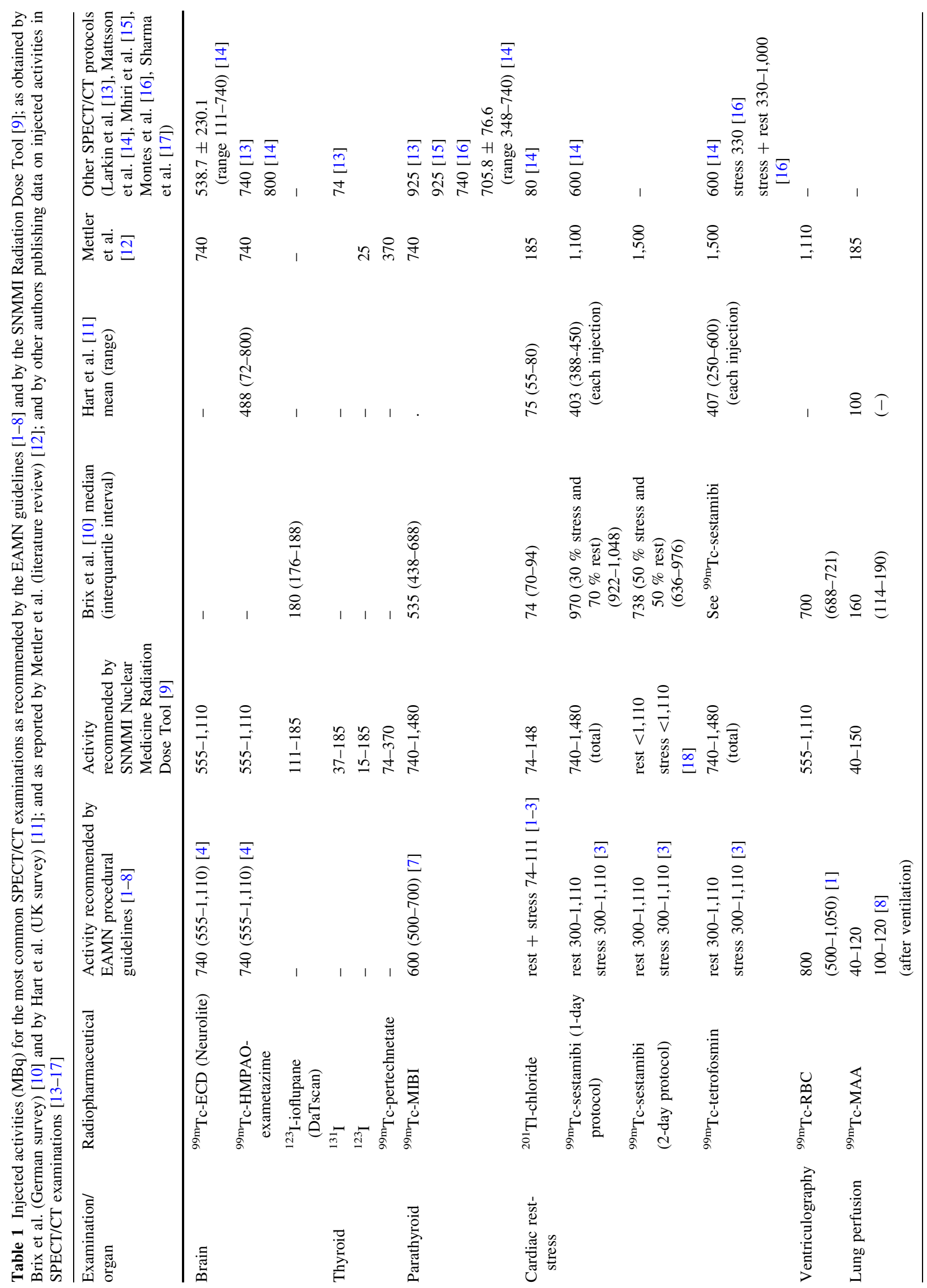




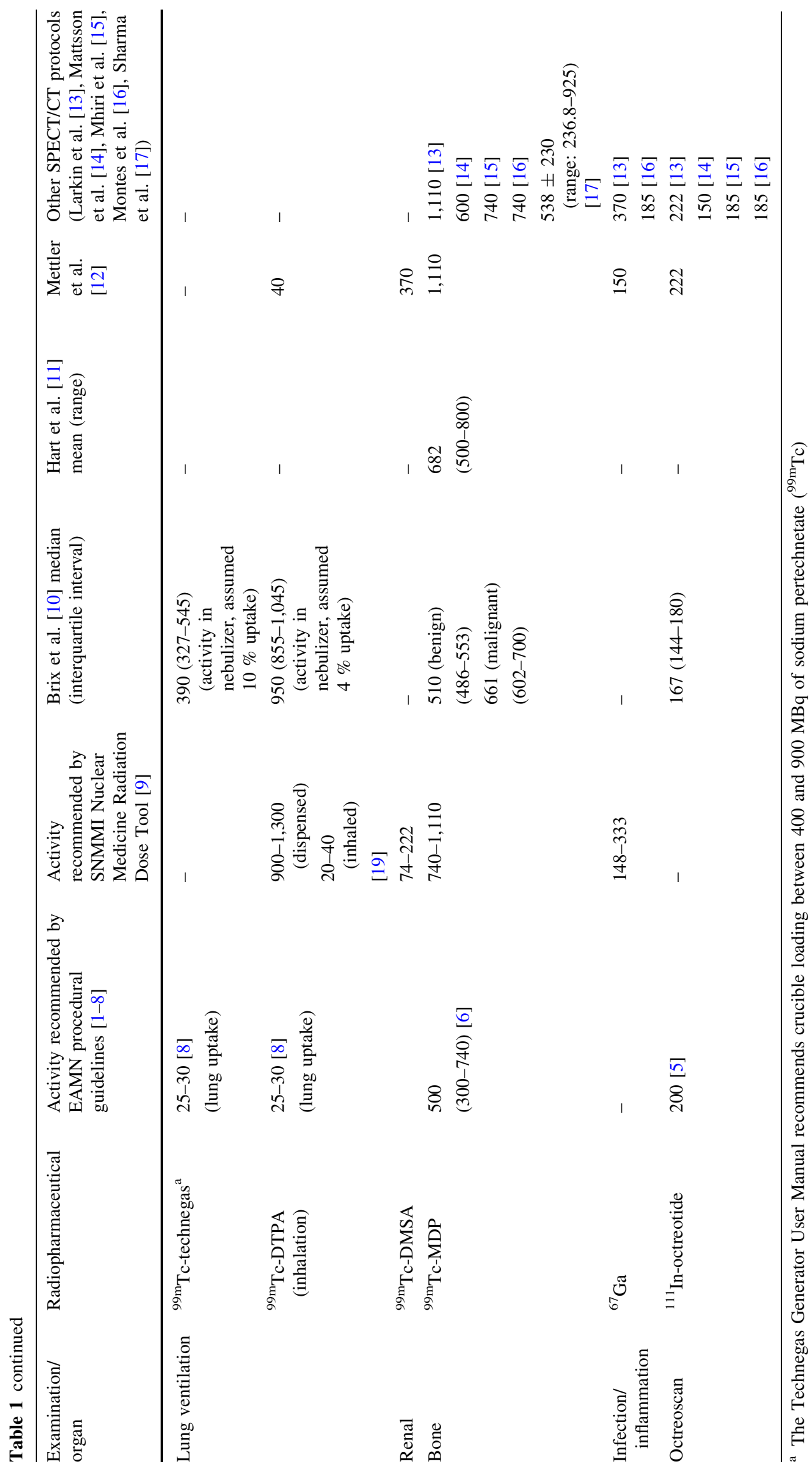


Table 2 Effective dose coefficients per unit of administered activity (mSv/MBq) adapted by the SNMMI [9] from ICRP 106 [22] for men and women, and those calculated by Brix et al. [10] using the effective dose definition recommended in ICRP 103 [24]

\begin{tabular}{|c|c|c|c|c|c|c|c|}
\hline \multirow[t]{2}{*}{ Examination/organ } & \multirow[t]{2}{*}{ Radiopharmaceutical } & \multicolumn{2}{|c|}{$\begin{array}{l}\text { Effective dose (ICRP 60) per } \\
\text { MBq (mSv) (SNMMI [9]) }\end{array}$} & \multirow{2}{*}{$\begin{array}{l}\text { Effective dose (ICRP } \\
\text { 103) per MBq (mSv) } \\
\text { (Brix et al. [10]) } \\
\text { Men }\end{array}$} & \multirow[t]{2}{*}{ Critical organ } & \multicolumn{2}{|c|}{$\begin{array}{l}\text { Mean absorbed } \\
\text { dose per MBq } \\
(\mathrm{mGy})(\mathrm{SNMMI} \\
[9])\end{array}$} \\
\hline & & Men & Women & & & Men & Women \\
\hline \multirow[t]{3}{*}{ Brain } & ${ }^{99} \mathrm{~m}_{\mathrm{Tc}} \mathrm{ECD}$ (Neurolite) & 0.008 & 0.010 & - & Bladder & 0.05 & 0.06 \\
\hline & ${ }^{99 \mathrm{~m}}$ Tc-HMPAO (Ceretec) & 0.009 & 0.011 & - & Kidneys & 0.03 & 0.04 \\
\hline & ${ }^{123}$ I-ioflupane (DaTscan) & 0.024 & - & 0.04 & Bladder & 0.05 & - \\
\hline \multirow[t]{3}{*}{ Thyroid } & ${ }^{131} \mathrm{I}$ & 0.072 & 0.088 & - & Bladder & 0.61 & 0.75 \\
\hline & ${ }^{123} \mathrm{I}$ & 0.013 & 0.016 & - & Bladder & 0.09 & 0.11 \\
\hline & ${ }^{99 \mathrm{~m}}$ Tc-pertechnetate & 0.013 & 0.017 & - & $\begin{array}{l}\text { Upper large } \\
\text { intestine }\end{array}$ & 0.06 & 0.07 \\
\hline Parathyroid & ${ }^{99 \mathrm{~m}} \mathrm{Tc}-\mathrm{MIBI}$ & 0.009 & 0.012 & $0.0,068$ & Gallbladder & 0.04 & 0.05 \\
\hline \multirow[t]{4}{*}{ Cardiac rest-stress } & ${ }^{201}$ Tl-chloride & 0.140 & 0.200 & 0.12 & Kidneys & 0.48 & 0.58 \\
\hline & ${ }^{99 \mathrm{~m}}$ Tc-sestamibi & 0.0079 stress & 0.010 stress & 0.0059 stress & Gallbladder & 0.03 & 0.04 \\
\hline & & 0.009 rest & 0.012 rest & 0.0068 rest & & & \\
\hline & ${ }^{99 \mathrm{~m}} \mathrm{Tc}$-tetrofosmin & 0.007 & 0.009 & $\begin{array}{l}0.0058 \text { stress } \\
0.0062 \text { rest }\end{array}$ & Gallbladder & 0.03 & 0.03 \\
\hline Ventriculography & ${ }^{99 \mathrm{~m}} \mathrm{Tc}-\mathrm{RBC}$ & 0.007 & 0.009 & 0.011 & Heart wall & 0.02 & 0.03 \\
\hline Lung perfusion & ${ }^{99 \mathrm{~m}}$ Tc-MAA & 0.011 & 0.016 & 0.013 & Lungs & 0.07 & 0.10 \\
\hline \multirow[t]{2}{*}{ Lung ventilation } & ${ }^{99 \mathrm{~m}}$ Tc-aerosol (Technegas) & 0.015 & 0.022 & 0.017 & Lungs & 0.11 & 0.16 \\
\hline & ${ }^{99 \mathrm{~m}}$ Tc-DTPA (inhalation) & 0.006 & 0.008 & 0.0034 & Bladder & 0.07 & 0.08 \\
\hline Renal & ${ }^{99 \mathrm{~m}}$ Tc-DMSA & 0.016 & 0.019 & - & Kidneys & 0.17 & 0.21 \\
\hline Bone & ${ }^{99 \mathrm{~m}}$ Tc-MDP & 0.006 & 0.007 & 0.004 & Bone surface & 0.06 & 0.08 \\
\hline Infection/inflammation & ${ }^{67} \mathrm{Ga}$ & 0.100 & 0.130 & - & Bone surface & 0.63 & 0.81 \\
\hline Octreoscan & ${ }^{111}$ In-octreotide & 0.054 & 0.071 & 0.059 & Spleen & 0.57 & 0.79 \\
\hline
\end{tabular}

For each examination, the critical organ and the absorbed dose coefficients are also reported for men and women (SNMMI [9])

\section{Choice of radiopharmaceutical}

It is appropriate, when faced with comparable clinical information, to use radiopharmaceuticals with shorter physical and biological half-lives (e.g., ${ }^{99 \mathrm{~m}} \mathrm{Tc}$ vs ${ }^{201} \mathrm{Tl}$ ) and generally those that result in lower doses (Tables 1,2$)$.

\section{New reconstruction algorithms}

The introduction of accelerated algorithms and advances in computing technology allowed the development of iterative image reconstruction with resolution recovery. Iterative reconstruction (IR) methods use slightly different algorithms but they are all based on the same concept: IR works in different loops, in which the image reconstructed from the projection data is compared to the "best estimate" of the image made by the software. According to the complexity of the process, corrections are made and the comparison is repeated until the deviation between the reconstructed image and the "best estimate" becomes acceptable. The major manufacturers now offer implementations of the ordered subset expectation maximization (OSEM) reconstruction method with distance-dependent resolution modeling (Wide Beam Reconstruction$\mathrm{WBR}^{\mathrm{TM}}$ _Ultraspect, Haifa, Israel; Evolution for Cardiac-GE Medical Systems, Waukesha, WI, USA; Astonish-Philips Healthcare, Eindhoven, The Netherlands; Flash3D-Siemens Medical Solution USA, Inc.). The new algorithms are available in commercial software, and their use is feasible within clinically practical times.

These new algorithms are designed to reduce noise, improving lesion identification without affecting image resolution. They make it possible to obtain the same image quality with a smaller number of collected counts, in other words to reduce the injected activity or the acquisition time of the examination.

Different studies have been conducted in different fields of application.

- Leva et al. [25] and Marcassa et al. [26] showed that the use of new IR algorithms makes it possible to perform 
either half-time or half-dose cardiac SPECT examinations, obtaining image quality and quantitative data comparable to those of standard-time or standard-dose SPECT.

- Livieratos et al. [27] assessed the commercial 3DOSEM algorithm (Philips Astonish), evaluating its performance in bone scintigraphy $\left({ }^{99 \mathrm{~m}} \mathrm{Tc}-\mathrm{MDP}\right)$. The results of this study showed that OSEM with the distance-dependent spatial resolution model can be used for image reconstruction in bone ${ }^{99 \mathrm{~m}} \mathrm{Tc}-\mathrm{MDP}$ SPECT studies at half the acquisition time or injected activity without compromising the image quality or reducing the diagnostic value of the examination.

- Albridge et al. [28] investigated "Evolution for bone SPECT" (GE Healthcare Technologies, Milwaukee, Wisconsin, USA), a new model-based corrective image reconstruction algorithm that compensates for image degradation due to collimator-detector characteristics, photon attenuation and scatter in the body, applying it to bone scintigraphic procedures as well as in parathyroid imaging. They demonstrated that the corrective algorithm improved image quality compared with filtered back projection (FBP) and OSEM. As a result of this study, this software is now routinely used in clinical practice, and SPECT acquisition time has been reduced from 30 to $15 \mathrm{~min}$ in the case of parathyroid SPECT examination and from 20 to $10 \mathrm{~min}$ for bone SPECT. This has improved patient comfort as the duration of scanning was one reason for non-compliance. In addition, potential movement artifacts are reduced as length of scanning time is decreased and patient throughput is increased. Of course, this potential for reducing scanning time while maintaining image quality can also be used for reducing administered activity and else patient dose.

\section{High-sensitivity collimators}

Special collimators, designed to magnify a specific region, provide higher acquisition sensitivity for specific organ examinations.

A variable focus collimator was developed by Siemens retaining the magnifying properties of a cone-beam collimator near the center of the field of view and eliminating the truncation artifacts at the edges of the field of view that are common to pinhole and focusing collimators. Imbert et al. [29] found a three-fold improved count sensitivity for this collimator with respect to conventional parallel-hole collimators. The use of this collimator, added to a cardiocentric acquisition and to the IQ SPECT reconstruction method, allowed the collection of up to four times as many counts from the heart during a myocardial perfusion SPECT study (Slomka et al. [30]).

New high-efficiency camera systems with more sensitive detectors

New camera systems specifically for cardiac examinations were recently introduced. These systems are based on new multiple solid-state high-efficiency detectors (cadmium zinc telluride-CdZnTe) and optimized acquisition geometry, collimator design, and reconstruction software.

The CdZnTe detectors are pixelated and the number of photons, which are counted on each detector, results in a directly measurable electrical signal. CdZnTe detectors are characterized by an excellent energy resolution (typically $<6 \%$ ), meaning that energy discrimination can be greatly improved, and by a very good response to high count rates.

These devices provide a four- to seven-fold improvement in sensitivity compared with a conventional dualdetector SPECT with higher resolution and contrast-tonoise ratio (CNR) (Imbert et al. [29]).

Using a GE Medical Systems Discovery NM 530c system with stationary pinhole collimators and an OSEMtype reconstruction algorithm, Duvall et al. [31] found, with respect to conventional SPECT at comparable or improved image quality and diagnostic accuracy, a significant reduction of administered activities (185 MBq for ${ }^{99 \mathrm{~m}} \mathrm{Tc}$ rest acquisition and $555 \mathrm{MBq}$ for ${ }^{99 \mathrm{~m}} \mathrm{Tc}$ stress acquisition) and of scan times (5 min for ${ }^{99 \mathrm{~m}} \mathrm{Tc}$ rest acquisition and $3 \mathrm{~min}$ for ${ }^{99 \mathrm{~m}} \mathrm{Tc}$ stress acquisition, compared to a 15-min conventional SPECT acquisition).

\section{Pregnancy}

Compared with routine medical radiation practices, the medical radiation exposure of a pregnant patient carries additional ethical considerations. This situation demands stricter application of the principle of justification and greater attention to optimization even though most nuclear medicine procedures do not cause large fetal doses [32].

For most of the radiopharmaceuticals used, which do not cross the placenta, the fetal dose is due to radioactivity in maternal tissues. There are, however, some radiopharmaceuticals, such as ${ }^{131}$ I-sodium iodide, which do cross the placenta and concentrate in specific organs or tissues. In such cases, the fetal self-dose contribution must be added. Table 3 shows absorbed doses to the fetus per unit of administered activity to the mother at different stages of gestation (from the early stages of pregnancy up to nine months) for the radiopharmaceuticals most widely used in SPECT/CT examinations as reported by the SNMMI [9]. 
Since radionuclides in maternal tissues contribute to the fetal dose; maternal hydration and frequent voiding can reduce the fetal dose after the administration of a number of radiopharmaceuticals. Absorbed dose to the fetus can also be reduced using longer imaging times and thus smaller administered activities.

\section{Pediatric examinations}

Although radiation exposures in children undergoing diagnostic nuclear medicine studies are low [34], such exposures can be further reduced by optimizing routine protocols, by applying advanced image processing, and potentially using advanced imaging systems.

Despite the longstanding use of nuclear medicine in pediatrics, the question of the standardization of pediatricadministered radiopharmaceutical activities has only recently been addressed. In 2014, the EANM and the SNMMI both suggested changes in their respective guidelines on administered activities for pediatric nuclear medicine in order to achieve a level of harmonization [35].

The SNMMI developed a tool that provides recommended injected activity for pediatric patients based on the North American consensus guidelines and the European Association of Nuclear Medicine guidelines (http://www. snmmi.org/ClinicalPractice/PaediatricTool.aspx).

Table 4 shows the administered activities for the most common pediatric examinations together with the effective dose coefficients. Data are reported for four different ages: 1, 5, 10, and 15 years. Effective dose (ICRP 60) coefficients were obtained from ICRP publications 80 [21] and 106 [22] and were calculated considering the mathematical phantoms described by Cristy and Eckerman [36].

Administered activities can be reduced through conventional system optimization by selecting the most appropriate collimator in relation to the patient size and the clinical task [34].

Using advanced image processing and reconstruction techniques in SPECT, as already outlined for adults, it is

Table 3 Absorbed doses to the fetus per unit of activity administered to the mother at different stages of gestation (first stages of pregnancy, 3 , 6, and 9 months) for the radiopharmaceuticals most widely used in SPECT/CT examinations as reported by the SNMMI [9]

\begin{tabular}{|c|c|c|c|c|c|}
\hline $\begin{array}{l}\text { Examination/ } \\
\text { organ }\end{array}$ & Radiopharmaceutical & $\begin{array}{l}\text { Fetus of a woman in } \\
\text { early stages of } \\
\text { pregnancy: absorbed } \\
\text { dose per } \mathrm{MBq}(\mathrm{mGy} / \\
\mathrm{MBq})\end{array}$ & $\begin{array}{l}\text { Fetus of a 3-month } \\
\text { pregnant woman: } \\
\text { absorbed dose per } \\
\text { MBq (mGy/MBq) }\end{array}$ & $\begin{array}{l}\text { Fetus of a 6-month } \\
\text { pregnant woman: } \\
\text { absorbed dose per } \\
\mathrm{MBq}(\mathrm{mGy} / \mathrm{MBq})\end{array}$ & $\begin{array}{l}\text { Fetus of a 9-month } \\
\text { pregnant woman: } \\
\text { absorbed dose per } \\
\text { MBq (mGy/MBq) }\end{array}$ \\
\hline \multirow[t]{2}{*}{ Brain } & $\begin{array}{l}{ }^{99 \mathrm{~m}} \text { Tc-ECD } \\
\text { (Neurolite) }\end{array}$ & 0.0114 & 0.0091 & 0.0056 & 0.0042 \\
\hline & $\begin{array}{c}{ }^{99 \mathrm{~m}} \mathrm{Tc}-\mathrm{HMPAO} \\
(\text { Ceretec) }\end{array}$ & 0.0087 & 0.0067 & 0.0048 & 0.0036 \\
\hline \multirow[t]{3}{*}{ Thyroid } & ${ }^{131} \mathrm{I}$ & $0.0668\left(0.072^{\mathrm{a}}\right)$ & $0.051\left(0.068^{\mathrm{a}}\right)$ & $0.213\left(0.23^{\mathrm{a}}\right)$ & $0.259\left(0.27^{\mathrm{a}}\right)$ \\
\hline & ${ }^{123} \mathrm{I}$ & $0.0196\left(0.02^{\mathrm{a}}\right)$ & $0.0087\left(0.014^{\mathrm{a}}\right)$ & $0.0062\left(0.011^{\mathrm{a}}\right)$ & $0.0062\left(0.0098^{\mathrm{a}}\right)$ \\
\hline & ${ }^{99 \mathrm{~m}}$ Tc-pertechnetate & 0.011 & 0.022 & 0.014 & 0.0093 \\
\hline Parathyroid & ${ }^{99 \mathrm{~m}} \mathrm{Tc}-\mathrm{MIBI}$ & 0.015 & 0.012 & 0.0084 & 0.0054 \\
\hline \multirow{4}{*}{$\begin{array}{l}\text { Cardiac rest- } \\
\text { stress }\end{array}$} & ${ }^{201}$ Tl-chloride & 0.097 & 0.058 & 0.047 & 0.027 \\
\hline & ${ }^{99 \mathrm{~m}} \mathrm{Tc}$-sestamibi & 0.012 stress & 0.0095 stress & 0.0069 stress & 0.0044 stress \\
\hline & & 0.015 rest & 0.012 rest & 0.0084 rest & 0.0054 rest \\
\hline & ${ }^{99 \mathrm{~m}} \mathrm{Tc}$-tetrofosmin & 0.0096 & 0.007 & 0.0054 & 0.0036 \\
\hline Ventriculography & ${ }^{99 \mathrm{~m}} \mathrm{Tc}-\mathrm{RBC}$ & 0.0064 & 0.0043 & 0.0033 & 0.0027 \\
\hline Lung perfusion & ${ }^{99 \mathrm{~m}} \mathrm{Tc}-\mathrm{MAA}$ & 0.0028 & 0.004 & 0.005 & 0.004 \\
\hline \multirow[t]{2}{*}{ Lung ventilation } & $\begin{array}{r}{ }^{99 \mathrm{~m}} \text { Tc-aerosol } \\
\text { (Technegas) }\end{array}$ & 0.0005 & 0.0004 & 0.0005 & 0.0006 \\
\hline & $\begin{array}{c}{ }^{99 \mathrm{~m}} \mathrm{Tc}-\mathrm{DTPA} \\
\text { (aerosol) }\end{array}$ & 0.0058 & 0.0043 & 0.0023 & 0.003 \\
\hline Renal & ${ }^{99 m}$ Tc-DMSA & 0.0051 & 0.0047 & 0.004 & 0.0034 \\
\hline Bone & ${ }^{99 \mathrm{~m}} \mathrm{Tc}-\mathrm{MDP}$ & 0.0061 & 0.0054 & 0.0027 & 0.0024 \\
\hline $\begin{array}{l}\text { Infection/ } \\
\text { inflammation }\end{array}$ & ${ }^{67} \mathrm{Ga}$ & 0.093 & 0.2 & 0.18 & 0.13 \\
\hline Octreoscan & ${ }^{111}$ In-octreotide & 0.082 & 0.06 & 0.035 & 0.031 \\
\hline
\end{tabular}

${ }^{a}$ Maternal and fetal self-dose contribution [33] 
Table 4 Administered activities and effective dose coefficients [21, 22] for the most common pediatric examinations

\begin{tabular}{|c|c|c|c|c|c|}
\hline Examination/organ & Radiopharmaceutical & Age (weight) & $\begin{array}{l}\text { North American } \\
\text { consensus } \\
\text { recommendations }(\mathrm{MBq})\end{array}$ & $\begin{array}{l}\text { EANM } \\
\text { recommendations } \\
(\mathrm{MBq})\end{array}$ & $\begin{array}{l}\text { Effective dose } \\
\text { coefficients } \\
(\mathrm{mSv} / \mathrm{MBq})\end{array}$ \\
\hline \multirow[t]{4}{*}{ Lung perfusion } & \multirow[t]{4}{*}{${ }^{99 \mathrm{~m}} \mathrm{Tc}-\mathrm{MAA}$} & 1 year $(9.1 \mathrm{~kg})$ & 15 & 14 & 0.063 \\
\hline & & 5 years $(18.1 \mathrm{~kg})$ & 20 & 25 & 0.034 \\
\hline & & 10 years $(30.6 \mathrm{~kg})$ & 34 & 39 & 0.023 \\
\hline & & 15 years $(54 \mathrm{~kg})$ & 60 & 64 & 0.016 \\
\hline \multirow[t]{4}{*}{ Renal } & \multirow[t]{4}{*}{${ }^{99 \mathrm{~m}} \mathrm{Tc}-\mathrm{DMSA}$} & 1 year $(9.1 \mathrm{~kg})$ & 19 & 19 & 0.037 \\
\hline & & 5 years $(18.1 \mathrm{~kg})$ & 33 & 30 & 0.021 \\
\hline & & 10 years $(30.6 \mathrm{~kg})$ & 57 & 48 & 0.015 \\
\hline & & 15 years $(54 \mathrm{~kg})$ & 100 & 78 & 0.011 \\
\hline \multirow[t]{4}{*}{ Bone } & \multirow[t]{4}{*}{${ }^{99 \mathrm{~m}} \mathrm{Tc}-\mathrm{MDP}$} & 1 year $(9.1 \mathrm{~kg})$ & 84 & 85 & 0.027 \\
\hline & & 5 years $(18.1 \mathrm{~kg})$ & 167 & 155 & 0.014 \\
\hline & & 10 years $(30.6 \mathrm{~kg})$ & 283 & 245 & 0.011 \\
\hline & & 15 years $(54 \mathrm{~kg})$ & 500 & 400 & 0.007 \\
\hline
\end{tabular}

Data are reported for four different pediatric ages: $1,5,10$, and 15 years

Table 5 Effective doses delivered to patients in the most common SPECT/CT examinations, as reported in recent literature

\begin{tabular}{clll}
\hline Study type & $\begin{array}{l}\text { Effective dose from } \\
\text { radiopharmaceuticals } \\
(\mathrm{mSv})\end{array}$ & $\begin{array}{l}\text { Effective dose } \\
\text { from CT } \\
\text { component } \\
(\mathrm{mSv})\end{array}$ & $\begin{array}{l}\% \\
\text { increase } \\
\text { due to } \\
\mathrm{CT}\end{array}$ \\
\hline${ }^{99 \mathrm{~m}}$ Tc-MIBI & 8.3 & 5.4 & $65.1 \%$ \\
parathyroid & 6.4 & 1.6 & 25.0 \\
{$[13,16,17]$} & 6.4 & 1.2 & 18.8 \\
${ }^{99 \mathrm{~m}}$ Tc-MDP & 6.3 & 3.8 & 60.3 \\
{$[13,17]$} & 4.1 & 4.2 & 102.4 \\
${ }^{111}$ In- & 12 & 7.0 & 58.3 \\
octreotide & 8.5 & 2.6 & 30.6 \\
{$[13,16]$} & 37 & 8.5 & 23.0 \\
${ }^{67}$ Gallium & $26.5 / 18.9^{\mathrm{a}}$ & 2.6 & $10 / 13.7^{\mathrm{a}}$ \\
{$[13,16]$} &
\end{tabular}

${ }^{a}$ Lymphoma and infection, respectively

possible to achieve significant reductions in radiopharmaceutical administered activities, without any loss of diagnostic information, also for children.

Sheehy et al. [37] compared two methods of reconstructing ${ }^{99 \mathrm{~m}}$ Tc-DMSA renal SPECT data-3D-OSEM and FBP - in children, considering their capacity to improve image quality and reduce the radiopharmaceutical activity and radiation dose. The results of the study demonstrated the possibility of obtaining, with 3D-OSEM, superior SPECT image quality with fewer counts than are used in FBP. The ability to reconstruct SPECT data with $50 \%$ fewer counts made it possible to simulate a corresponding $50 \%$ reduction in administered radiopharmaceutical activity, which in turn would lead to a $50 \%$ reduction in radiation dose to the patient. Alternatively, still using 3D-
OSEM, it is possible to reduce scanning times by half and thus effectively increase patient comfort and potentially minimize the need to sedate young patients who undergo ${ }^{99}$ Tc- DMSA SPECT examinations.

The same issue was validated by Stansfield et al. [38] using 3D-OSEM with resolution recovery in skeletal ${ }^{99} \mathrm{~m}$ Tc-MDP SPECT examinations.

\section{The CT component}

In hybrid SPECT/CT imaging, functional information provided by SPECT is complemented by structural information provided by $\mathrm{CT}$ that serves different purposes such as attenuation correction (AC), anatomical localization, and sometimes even diagnosis.

The first SPECT/CT systems were equipped only with older CT devices and thus produced low-quality clinical images suitable only for AC and localization, but not for additional diagnostic purposes.

The most recent SPECT/CTs, however, incorporate lastgeneration CT scanners, which provide detailed anatomical images of patients and thus allow further clinical CT diagnoses. As regards their dose contribution, these scanners can account for a considerable percentage of the dose of the whole SPECT/CT examination, as reported in Table 5 [13, 16, 17]. Buck et al. [39], with reference to SPECT-guided diagnostic $\mathrm{CT}$, report a radiation dose, additional to that of the radiopharmaceutical, of $6-14 \mathrm{mSv}$ depending on the field of view in $\mathrm{z}$-axis.

It is therefore very important that, rather than applying standard protocols, combined SPECT/CT procedures can be selected on an individual basis and reflect clinical needs. 
As a general rule, low-dose acquisition is suggested when recent diagnostic $\mathrm{CT}$ data are available and when follow-up studies are to be performed (monitoring of response to treatment). Moreover, low-dose CT is indicated for further anatomical localization or characterization of focal pathology present on planar or SPECT images. SPECTguided diagnostic CT is instead suggested when a recent diagnostic CT is not available and when detailed anatomical information is mandatory to address clinical needs.

Hulme et al. [40] demonstrated that AC is achievable with ultra-low-dose CT, despite the high CT image noise, without compromising the quality of the SPECT image. In fact they showed that, in the case of the Symbia True Point (T16, Siemens Medical Solutions USA, Inc.) system, CT noise levels corresponding to CT dose indexes $\left(\mathrm{CTDI}_{\mathrm{vol}}\right)$ down to $\approx 4 \mu \mathrm{Gy}$ did not affect SPECT quantification. Therefore, the need of higher doses for the CT component of SPECT/CT is imposed by image quality requirements for anatomical localization and artifact reduction.

While Buck et al. indicate a dose range from 2 to $4 \mathrm{mSv}$ for SPECT-guided low-dose CT [39], Roach et al. showed that CT scans used for anatomical localization in the chest or abdomen release up to 1-2 mSv [41], Sawyer et al. [42] reported typical values of around $1.1 \mathrm{mSv}$ for the chest, around $1.3 \mathrm{mSv}$ for abdomen-pelvis and around $0.2 \mathrm{mSv}$ for the head, and Montes et al. [15] reported similar values $(\approx 1.2 \mathrm{mSv})$ for chest and abdomen-pelvis and $0.6 \mathrm{mSv}$ for the head-neck region.

Miller [43] showed even lower radiation exposure for the CT scan of the SPECT/CT examination: $0.47 \mathrm{mSv}$ for an abdominal non-diagnostic localization and AC scan. The datum was also confirmed by Kneifel who assessed an effective dose of $0.5 \mathrm{mSv}$ with the GE Hawkeye equipment [44].

\section{CT dose optimization}

The dose dependence, in CT, on acquisition parameters such as tube potential, tube load, rotation time, beam width, pitch, and reconstructed image thickness should be considered when addressing the need for CT dose optimization [45].

Furthermore, it is well known that CT scanning is also a patient-dependent modality: patient size can greatly influence the acquisition for particular body regions, necessitating different settings in different patients. In abdominal $\mathrm{CT}$, for example, the tube potential should be adjusted from $80 \mathrm{kVp}$ for very thin patients to $140 \mathrm{kVp}$ for severely obese patients.

In particular, special care should be taken with children, who, due to the higher radiosensitivity of growing tissues and their longer life expectancy, are exposed to a higher radiation risk in a CT examination [46].
Good image quality in children can be achieved with lower tube potential and tube load values, thus reducing the dose delivered.

Dose increase in CT practice [47], combined or not with other modalities, has prompted manufacturers to study and propose new dose-reduction methods in order to limit the individual radiation exposure. This reduction should, however, be performed without sacrificing the diagnostic quality of the images, which must remain acceptable.

Three main improvements have been introduced for this purpose: automatic tube current modulation (ATCM), automatic tube voltage selection (ATVS), and IR algorithms instead of the "classic" FBP method.

\section{Automatic tube current modulation (ATCM)}

Automatic tube current modulation is a solution, now implemented in all commercial CTs, whose aim is to reduce the dose delivered to the patient fixing the image quality and adapting tube current $(\mathrm{mA})$ to the patient's size and anatomy and generating images of diagnostic quality.

ATCM can work in three dimensions by combining patient size-modulation, z-axis-longitudinal modulation adjusting current during table feed, and xy-axis-angular modulation with current adjustment during gantry rotation.

The ATCM uses the attenuation information from one or both scouts and also takes into consideration the operatorchosen image quality, selecting the vendor's specific parameter: reference mAs (Siemens), standard deviation (Toshiba), Noise Index (General Electric), and reference images (Philips).

If properly used, ATCM allows, compared with a fixed tube current (FTC), a better dose distribution with higher $\mathrm{mA}$ to denser tissues and lower $\mathrm{mA}$ to more radiotransparent ones, like the lungs.

The dose-reducing effectiveness of ATCM compared to FTC has been demonstrated in several studies [48-50] with Lee et al. [48] showing an average reduction of $45 \%$ in the abdomen and pelvis CT with images of an acceptable diagnostic level.

\section{Organ-based and automatic $k V$ selection}

Some systems also provide for organ-based tube current modulation, which can reduce the dose to radiosensitive organs close to the surface of the body. The mammary glands, thyroid glands, and eye lenses thus receive a lower dose as the system reduces the tube current when the tube comes close to these organs. To compensate for this reduction, the tube current in the $\mathrm{X}$-ray projection from the opposite side is increased thus leaving mean image noise constant $[51,52]$. This application can be very useful in 
SPECT/CT systems for sparing the lens in CT head acquisitions, as SPECT/CT can acquire only axial and not transaxial images with tilted gantry, because of problems in image registration. Bismuth shielding, placed over the organ of interest to attenuate the X-ray beam entering the patient, has also been used to reduce the dose from CT to anterior radiosensitive organs, such as the breast, lens of the eye, and thyroid [53]. However, the AAPM [54] recommends that the use of bismuth shielding should be carefully considered and that organ-based tube current modulation should be implemented when possible.

Since the radiation dose changes with roughly the square of the tube potential, attention turned to the possibility of introducing automatic tube voltage selection (ATVS) [55, 56] in addition to ATCM in order to acquire low-tubevoltage images.

ATVS automatically maintains a constant CNR, defined for a reference patient, by adjusting the scanning parameters, e.g., tube voltage $(\mathrm{kV})$ and tube current $(\mathrm{mA})$, taking into account the examination type, the body region, and the patient's body habitus.

\section{Iterative reconstruction}

Although FBP is the standard image reconstruction technique in $\mathrm{CT}$, it presents limitations, namely image noise increase and a worsening of the image quality on dose lowering.

Recently vendors, in order to overcome this problem, as already seen with tomoscintigraphic reconstruction, have developed new IR algorithms for reconstruction techniques, which in the past were avoided because of their excessively long computational time. These algorithms are often divided into hybrid IR and pure IR. The hybrid IR algorithms involve blending with FBP in order to keep the noise characteristics and image texture that radiologists are accustomed to. In pure IR algorithms, there is no blending with FBP.

Several systems are available commercially that feature different mixes of IR and FBP and thus result in diagnostic images having different appearances and allowing different dose savings [57, 58].

The role and the impact of IR algorithms have been investigated in several studies.

Christe et al. [59] reported an average dose reduction of up to $25 \%$ with IR, while maintaining the same subjective (i.e., evaluated by radiologists) image quality on a chest phantom acquired with different $\mathrm{kVp} / \mathrm{mAs}$ combinations. Kalmar et al. [60] studied the effect of the IR on 100 thoracic and abdominal CT scans, finding a dose reduction of 64 and $58 \%$, respectively, compared with FBP, with no clinically significant impact on image quality. Klink et al. [61] confirmed this trend after a study involving both phantom CT $\left(\mathrm{CTDI}_{\mathrm{vol}}\right.$ reduction of $26-50 \%$ using IR instead of FBP) and patient chest and abdominal CT, in which IR allowed lower tube voltage and current with the same image quality.

It has been found that ATCM, ATVS, and IR algorithms work even better together, allowing greater dose reductions in examinations of the chest [62-64], abdomen [62, 65], pelvis [65], and in coronary CT [66].

\section{Dose assessment in CT}

The two main dose descriptors in CT are the $\mathrm{CTDI}_{\mathrm{vol}}$ and the dose-length product (DLP). The $\mathrm{CTDI}_{\mathrm{vol}}$ indicates the estimated mean dose for a single slice, while the DLP, obtained by multiplying the $\mathrm{CTDI}_{\mathrm{vol}}$ by the scan length, estimates the overall radiation absorbed by the patient. The DLP is also useful for obtaining an approximate estimate of the effective dose to the patient. In fact the effective dose (E) can easily be evaluated by multiplying the DLP by a conversion coefficient $k$ specific for the anatomical region under examination $(E=k \times \mathrm{DLP}) ; k$ coefficients for adults (standard physique) and pediatric patients of various ages over various body regions, reported in the AAPM Report no. 96 [67], are shown in Table 6. Conversion factors for adult head and neck, and pediatric patients are referred to the head CT dose phantom $(16 \mathrm{~cm})$, while all other conversion factors are referred to the 32-cm-diameter
Table 6 Normalized effective dose per dose-length product (DLP) for adults (standard physique) and pediatric patients of various ages over various body regions

${ }^{\mathrm{a}} \mathrm{mSv} / \mathrm{mGycm}$

\begin{tabular}{|c|c|c|c|c|c|c|c|}
\hline \multirow[t]{2}{*}{ Region of body } & \multicolumn{5}{|c|}{$\mathrm{k}_{\text {ICRP60 }}{ }^{\mathrm{a}}[67]$} & \multirow{2}{*}{$\begin{array}{l}\mathrm{k}_{\text {ICRP103 }}{ }^{\mathrm{a}} \\
{[70]} \\
\text { Adult }\end{array}$} & \multirow{2}{*}{$\begin{array}{l}\mathrm{K}_{\mathrm{ICRP} 103} \\
{[71]} \\
\text { Adult }\end{array}$} \\
\hline & $\begin{array}{l}0 \text {-year } \\
\text { old }\end{array}$ & $\begin{array}{l}\text { 1-year } \\
\text { old }\end{array}$ & $\begin{array}{l}5 \text {-year } \\
\text { old }\end{array}$ & $\begin{array}{l}\text { 10-year } \\
\text { old }\end{array}$ & Adult & & \\
\hline Head and neck & 0.013 & 0.0085 & 0.0057 & 0.0042 & 0.0031 & - & 0.045 \\
\hline Head & 0.011 & 0.0067 & 0.0040 & 0.0032 & 0.0021 & 0.026 & 0.024 \\
\hline Neck & 0.017 & 0.012 & 0.011 & 0.0079 & 0.0059 & - & 0.053 \\
\hline Chest & 0.039 & 0.026 & 0.018 & 0.013 & 0.014 & 0.0199 & 0.0204 \\
\hline $\begin{array}{l}\text { Abdomen and } \\
\text { pelvis }\end{array}$ & 0.049 & 0.030 & 0.020 & 0.015 & 0.015 & 0.0163 & 0.0171 \\
\hline Trunk & 0.044 & 0.028 & 0.019 & 0.014 & 0.015 & 0.0178 & 0.0186 \\
\hline
\end{tabular}


CT body phantom $[68,69]$. Those coefficients $\left(\mathrm{k}_{\text {ICRP60 }}\right)$ refer to the effective dose as defined in ICRP 60. Recently, conversion coefficients were also evaluated by some authors taking into account the ICRP 103 definition [70, 71]. These ( $\left.\mathrm{k}_{\mathrm{ICRP} 103}\right)$ are also shown in Table 6 for comparison. A more detailed analysis has also been done by Deak et al. [72] who determined, for spiral scanning protocols with different voltages, sex- and age-specific conversion factors taking into account both the ICRP 60 and ICRP 103 effective dose definitions.

\section{Conclusions}

This review has provided ample information on the activities normally administered in SPECT/CT examinations and on the possibilities for patient dose optimization, which can be achieved both by carefully selecting and using appropriate equipment and by carefully considering each individual examination to be carried out.

It has also highlighted, with reference to the CT component, the importance, in the context of dose optimization, of taking into account the clinical need for the CT acquisition, as well as the use of the possible technological tools that can reduce patient exposure.

Finally, it has shown how patient dose can easily be determined in individual SPECT/CT examinations simply by considering administered activities and the DLP values reported in each CT examination.

\section{Acknowledgments Compliance with Ethics Guidelines}

Conflict of interest The authors of this review article (Mahila Ferrari, Paolo De Marco, Daniela Origgi, and Guido Pedroli) declare that they have no conflict of interest.

Human and animal studies This article does not contain any studies with human or animal subjects performed by any of the authors.

\section{References}

1. Hesse B, Lindhardt BT, Acampa W et al (2008) EANM/ESC guidelines for radionuclide imaging of cardiac function. Eur $\mathrm{J}$ Nucl Med Mol Imaging 35:851-885

2. Hesse B, Tagil K, Cuocolo A et al (2005) EANM/ESC procedural guidelines for myocardial perfusion imaging in nuclear cardiology. Eur J Nucl Med Mol Imaging 32:855-897

3. Flotats A, Knuuti J, Gutberlet M et al (2011) Hybrid cardiac imaging: SPECT/CT and PET/CT. A joint position statement by the European Association of Nuclear Medicine (EANM), the European Society of Cardiac Radiology (ESCR) and the European Council of Nuclear Cardiology (ECNC). Eur J Nucl Med Mol Imaging 38:201-212

4. Kapucu ÖL, Nobili F, Varrone A, Booji J, Vander Borght T, Någren K, Darcourt J, Tatsch K, Van Laere K (2009) EANM procedure guideline for brain perfusion SPECT using ${ }^{99 m} \mathrm{Tc}-$ labelled radiopharmaceuticals, version 2. Eur J Nucl Med Mol Imaging 36:2093-2102

5. Bombardieri E, Ambrosini V, Aktolun C et al (2010) ${ }^{111}$ In-pentetreotide scintigraphy: procedure guidelines for tumour imaging. Eur J Nucl Med Mol Imaging 37:1441-1448

6. Bombardieri E, Aktolun C, Baum RP et al (2003) Bone scintigraphy: procedure guidelines for tumour imaging. Eur J Nucl Med Mol Imaging 30:BP99-BP106

7. Hindié E, Ugur O, Fuster D et al (2009) EANM parathyroid guidelines. Eur J Nucl Med Mol Imaging 36:1201-1216

8. Bajc M, Neilly JB, Miniati M et al (2009) EANM guidelines for ventilation/perfusion scintigraphy. Eur J Nucl Med Mol Imaging 36:1356-1370

9. http://www.snmmi.org/ClinicalPractice/doseTool.aspx

10. Brix G, Nekolla EA, Borowski M, Noßke D (2014) Radiation risk and protection of patients in clinical SPECT/CT. Eur J Nucl Med Mol Imaging 41(Suppl 1):S125-S136

11. Hart D, Wall BF (2005) UK nuclear medicine survey 2003-2004. Nucl Med Commun 26:937-946

12. Mettler FA, Huda W, Yoshizumi TT, Mahesh M (2008) Effective doses in radiology and diagnostic nuclear medicine: a catalog. Radiology 248:254-263

13. Larkin AM, Serulle Y, Wagner S et al (2011) Quantifying the increase in radiation exposure associated with SPECT/CT compared to SPECT alone for routine nuclear medicine examinations. Int J Mol Imaging. doi:10.1155/2011/897202

14. Mattsson S, Soderberg M (2011) Radiation dose management in CT, SPECT/CT and PET/CT techniques. Radiat Prot Dosim 147:13-21

15. Mhiri A, Slim I, Ghezaiel M et al (2012) Estimation of radiation dosimetry for some common SPECT-CT exams. Int J Biotechnol Wellness Ind 1:266-269

16. Montes C, Tamayo P, Hernandez J et al (2013) Estimation of the total effective dose from low-dose CT scans and radiopharmaceutical administrations delivered to patients undergoing SPECT/ CT explorations. Ann Nucl Med 27:610-617

17. Sharma P, Sharma S, Ballal S, Bal C, Malhotra A, Kumar R (2012) SPECT-CT in routine clinical practice: increase in patient radiation dose compared with SPECT alone. Nucl Med Commun 33:926-932

18. Strauss HW, Miller DD, Wittry MD, Cerqueira MD, Garcia EV, Iskandrian AS, Schelbert HR, Wackers FJ, Balon HR, Lang O, Machac J (2008) Procedure guideline for myocardial perfusion imaging 3.3. J Nucl Med Technol 36:155-161

19. Parker JA, Coleman RE, Grady E, Royal HD, Siegel BA, Stabin MG, Sostman HD, Hilson AJ; Society of Nuclear Medicine (2012) SNM practice guideline for lung scintigraphy 4.0. J Nucl Med Technol 40:57-65

20. ICRP (1988) Radiation dose to patients from radiopharmaceuticals. ICRP Publication 53; Ann ICRP 18(1-4)

21. ICRP (1998) Radiation dose to patients from radiopharmaceuticals (Addendum to ICRP Publication 53). ICRP Publication 80; Ann ICRP 28(3)

22. ICRP (2008) Radiation dose to patients from radiopharmaceuticals-Addendum 3 to ICRP Publication 53. ICRP Publication 106; Ann ICRP 38(1-2)

23. ICRP (1991) Recommendations of the international commission on radiological protection. ICRP Publication 60; Ann ICRP 21(1-3)

24. ICRP (2007) The 2007 recommendations of the international commission on radiological protection. ICRP Publication 103; Ann. ICRP 37(2-4)

25. Leva L, Brambilla M, Matheoud R, Vigna L, Marino P, Inglese E (2012) The relationship between quantitative perfusion and functional results and acquisition time with reduced administered activity for ${ }^{99 \mathrm{~m}} \mathrm{Tc}$ tetrofosmin myocardial gated-SPECT. Clin Nucl Med 37:e162-e169 
26. Marcassa C, Campini R, Zoccarato O, Calza P (2011) Wide beam reconstruction for half-dose or half-time cardiac gated SPECT acquisitions: optimization of resources and reduction in radiation exposure. Eur J Nucl Med Mol Imaging 38:499-508

27. Livieratos L, Mohan H, Gnanasegaran G, Fogelman I (2010) Comparison of 10 versus 20 min SPECT ${ }^{99 \mathrm{~m}} \mathrm{Tc}-\mathrm{MDP}$ bone scans: use of 3D-OSEM image reconstruction with distance-dependent resolution modelling. Nucl Med Commun 31:1045-1053

28. Aldridge MD, Waddington WW, Dickson JC, Prakash V, Ell PJ, Bomanji JB (2013) Clinical evaluation of reducing acquisition time on single-photon emission computed tomography image quality using proprietary resolution recovery software. Nucl Med Commun 34:1116-1123

29. Imbert L, Poussier S, Franken PR, Songy B, Verger A, Morel O, Wolf D, Noel A, Karcher G, Marie PY (2012) Compared performance of high-sensitivity cameras dedicated to myocardial perfusion SPECT: a comprehensive analysis of phantom and human images. J Nucl Med 53:1897-1903

30. Slomka PJ, Berman DS, Germano G (2014) New cardiac cameras: single-photon emission CT and PET. Semin Nucl Med 44:232-251

31. Duvall WL, Croft LB, Ginsberg ES, Einstein AJ, Guma KA, George T, Henzlova MJ (2011) Reduced isotope dose and imaging time with a high-efficiency CZT SPECT camera. J Nucl Cardiol 18:847-857

32. ICRP (2000) Pregnancy and medical radiation. ICRP Publication 84. Ann ICRP 30(1)

33. Russell JR, Stabin MG, Sparks RB (1997) Placental transfer of radiopharmaceuticals and dosimetry in pregnancy. Health Phys 73:747-755

34. Treves ST, Falone AE, Fahey FH (2014) Pediatric nuclear medicine and radiation dose. Semin Nucl Med 44:202-209

35. Lassmann M, Treves ST EANM/SNMMI Paediatric Dosage Harmonization Working Group (2014) Paediatric radiopharmaceutical administration: harmonization of the 2007 EANM paediatric dosage card (version 1.5.2008) and the 2010 North American consensus guidelines. Eur J Nucl Med Mol Imaging 41:1036-1041

36. Cristy M, Eckerman KF (1987) Specific absorbed fractions of energy at various ages from internal photon sources. Parts I-VII. ORNL/TM-8381/V1-V7. Oak Ridge National Laboratory, Oak Ridge

37. Sheehy N, Tetrault TA, Zurakowski D, Vija AH, Fahey FH, Treves ST (2009) Pediatric ${ }^{99 \mathrm{~m}}$ Tc-DMSA SPECT performed by using iterative reconstruction with isotropic resolution recovery: improved image quality and reduced radiopharmaceutical activity. Radiology 251:511-516

38. Stansfield EC, Sheehy N, Zurakowski D, Vija AH, Fahey FH, Treves ST (2010) Pediatric ${ }^{99 m}$ Tc-MDP bone SPECT with ordered subset expectation maximization iterative reconstruction with isotropic 3D resolution recovery. Radiology 257:793-801

39. Buck AK, Nekolla S, Ziegler S, Beer A, Krause BJ, Herrmann K, Scheidhauer K, Wester HJ, Rummeny EJ, Schwaiger M, Drzezga A (2008) SPECT/CT. J Nucl Med 49:1305-1319

40. Hulme KW, Kappadath SC (2014) Implications of CT noise and artifacts for quantitative ${ }^{99 \mathrm{~m}} \mathrm{Tc}$ SPECT/CT imaging. Med Phys 41:1-10

41. Roach PJ, Schembri GP, Ho Shon IA, Bailey EA, Bailey DL (2006) SPECT/CT imaging using a spiral CT scanner for anatomical localization: impact on diagnostic accuracy and reporter confidence in clinical practice. Nucl Med Commun 27:977-987

42. Sawyer LJ, Starritt HC, Hiscock SC, Evans MJ (2008) Effective doses to patients from CT acquisitions on the GE Infinia Hawkeye: a comparison of calculation methods. Nucl Med Comm 29:144-149
43. Miller JC (2010) Hybrid SPECT/CT: enhancing nuclear medicine. Radiol Rounds 8(7). http://asoft10273.accrisoft.com/ snap043/clientuploads/july_2010/july_2010.pdf

44. Kneifel S (2003) Radiation dose and radiation protection. In: von Shultness GK (ed) Clinical molecular anatomic imaging. Lippincott, Philadelphia, pp 68-71

45. McCollough $\mathrm{CH}$ (2013) Standardization versus individualization: how each contributes to managing dose in computed tomography. Health Phys 105:445-453

46. Brenner D, Elliston C, Hall E, Berdon W (2001) Estimated risks of radiation-induced fatal cancer from pediatric CT. Am J Roentgenol 176:229-289

47. Mettler FA, Bhargavan M, Faulkner K et al (2009) Radiologic and nuclear medicine studies in the United States and worldwide: frequency, radiation dose and comparison with other radiation sources 1950-2007. Radiology 253:520-531

48. Lee S, Yoon SW, Yoo SM, Ji YG, Kim KA, Kim SH, Lee JT (2011) Comparison of image quality and radiation dose between combined automatic tube current modulation and fixed tube current technique in $\mathrm{CT}$ of abdomen and pelvis. Acta Radiol 52:1101-1106

49. Peng Y, Li J, Ma D, Zhang Q, Liu Y, Zeng J, Sun G (2009) Use of automatic tube current modulation with a standardized noise index in young children undergoing chest computed tomography scans with 64-slice multidetector computed tomography. Acta Radiol 50:1175-1181

50. Papadakis AE, Perisinakis K, Damilakis J (2008) Automatic exposure control in paediatric and adult multidetector CT examinations: a phantom study on dose reduction and image quality. Med Phys 35:4567-4576

51. Duan X, Wang J, Christner JA, Leng S, Grant KL, McCollough CH (2011) Dose reduction to anterior surfaces with organ-based tube-current modulation: evaluation of performance in a phantom study. AJR Am J Roentgenol 197:689-695

52. Kubo T, Ohno Y, Kauczor HU, Hatabu H (2014) Radiation dose reduction in chest CT-review of available options. Eur J Radiol 83:1953-1961

53. Hopper KD, King SH, Lobell ME, TenHave TR, Weaver JS (1997) The breast: inplane x-ray protection during diagnostic thoracic CT-shielding with bismuth radioprotective garments. Radiology 205:853-858

54. AAPM Position Statement on the Use of Bismuth Shielding for the Purpose of Dose Reduction in CT scanning. Statement approved by AAPM Board of Directors. Feb 2012-Policy Date 02/07/2012. www.aapm.org/publicgeneral/BismuthShielding.pdf

55. Goetti R, Winklehner A, Gordic S, Baumueller S, Karlo CA, Frauenfelder T, Alkadhi H (2012) Automated attenuation-based kilovoltage selection: preliminary observations in patients after endovascular aneurysm repair of the abdominal aorta. AJR Am J Roentgenol 199:W380-W385

56. Lee KH, Lee JM, Moon SK, Baek JH, Park JH, Flohr TG, Kim KW, Kim SJ, Han JK, Choi BI (2012) Attenuation based automatic tube voltage selection and tube current modulation for dose reduction at contrast-enhanced liver CT. Radiology 265:437-447

57. Raman SP, Johnson PT, Deshmukh S, Mahesh M, Grant KL, Fishman EK (2013) CT dose reduction applications: available tools on the latest generation of CT scanners. J Am Coll Radiol 10:37-41

58. Jensen K, Martinsen AC, Tingberg A, Aaløkken TM, Fosse E (2014) Comparing five different iterative reconstruction algorithms for computed tomography in an ROC study. Eur Radiol 24:2989-3002

59. Christe A, Heverhagen J, Ozdoba C, Weisstanner C, Ulzheimer S, Ebner L (2013) CT dose and image quality in the last three scanner generations. World J Radiol 5:421-429 
60. Kalmar PI, Quehenberger F, Steiner J et al (2014) The impact of iterative reconstruction on image quality and radiation dose in thoracic and abdominal CT. Eur J Radiol 83:1416-1420

61. Klink T, Obmann V, Heverhagen J, Stork A, Adam G, Begemann P (2014) Reducing CT radiation dose with iterative reconstruction algorithms: the influence of scan and reconstruction parameters on image quality and CTDI ${ }_{\mathrm{vol}}$. Eur J Radiol 83:1645-1654

62. Mayer C, Meyer M, Fink C, Schmidt B, Sedlmair M, Schoenberg SO, Henzler T (2014) Potential for radiation dose savings in abdominal and chest CT using automatic tube voltage selection in combination with automatic tube current modulation. AJR Am J Roentgenol 203:292-299

63. Chae IH, Kim Y, Lee SW, Park JE, Shim SS, Lee JH (2014) Standard chest CT using combined automated tube potential selection and iterative reconstruction: image quality and radiation dose reduction. Clin Imaging 38:641-647

64. Chen JH, Jin EH, He W, Zhao LQ (2014) Combining automatic tube current modulation with adaptive statistical iterative reconstruction for low-dose chest CT screening. PLoS ONE 9:e92414

65. Vardhanabhuti V, Loader R, Roobottom CA (2013) Assessment of image quality on effects of varying tube voltage and automatic tube current modulation with hybrid and pure iterative reconstruction techniques in abdominal/pelvic CT: a phantom study. Invest Radiol 48:167-174

66. Suh YJ, Kim YJ, Hong SR, Hong YJ, Lee HJ, Hur J, Choi BW (2013) Combined use of automatic tube potential selection with tube current modulation and iterative reconstruction technique in coronary CT angiography. Radiology 269:722-729
67. AAPM Report no 96 (2008) The Measusing, Reporting and Management of Radiation Dose in CT. Report of AAPM Task Group 23: CT Dosimetry-Diagnostic Imaging Council CT Committee. American Association of Physicists in Medicine, One Physics Ellipse, College Park, pp 20740-3846

68. Bongartz G, Golding S, Jurik A, Leonardi M, Geleijns J, Jessen KA, Panzer W, Shrimpton PC, van Persijn van Meerten E, Tosi G (2000) Guidelines on Radiation Dose to the Patient. EUR 16262-European Guidelines on Quality Criteria for Computed Tomography. Chapter 1, Appendix I:65-70, European Commission 2000

69. Shrimpton PC. Assessment of patient dose in CT. NRPB-PE/1/ 2004. NRPB, Chilton, 2004. Also published as Appendix C of Bongartz G, Golding S, Jurik A, Leonardi M, Geleijns J, Jessen KA, Panzer W, Shrimpton PC, van Persijn van Meerten E, Tosi G (2004) European Guidelines for Multislice Computed Tomography. European Commission 2004. at http://www.msct.eu/CT_ Quality_Criteria.htm

70. Elbakri I (2011) TH-E-211-03: DLP to effective dose conversion factors for CT based on ICRP 103. Paper presented at the Joint meeting of the American Association of Physicists in Medicine and the Canadian Organization of Medical Physics, Vancouver 2011. Med Phys 38:3876. http://dx.doi.org/10.1118/1.3613598

71. Huda W, Magill D, He W (2011) CT effective dose per dose length product using ICRP 103 weighting factors. Med Phys 38:1261-1265

72. Deak PD, Smal Y, Kalender WA (2010) Multisection CT protocols: sex- and age-specific conversion factors used to determine effective dose from dose-length product. Radiology 257:158-166 